\title{
MAIROKANG BEACH GAME (MBG) SEBAGAI POTENSI PARIWISATA PESISIR DI DESA BENTUNG, KABUPATEN KEPULAUAN SANGIHE
}

\author{
Aldy Tatali ${ }^{1}$ \\ 1)Mahasiswa Pascsarjana PS. IImu Perairan Fakultas Perikanan dan IImu Kelautan \\ Universitas Sam Ratulangi Manado \\ Koresponden email : aldy07tatali@gmail.com
}

\begin{abstract}
Sangihe Islands Regency which is a maritime district has several Tourism Strategic Areas which have the main function of tourism or have the potential for tourism development and have an important influence in one or more aspects such as economic, social and cultural growth, empowerment of natural resources, environmental carrying capacity, defense and security. Bentung Village in South Tabukan is one of the villages in the Sangihe Islands Regency which has potential in coastal tourism. Mairokang Beach Game (MBG) is a traditional boat race that is one of the potential of coastal tourism in Bentung Village. This research focuses on tourism potential embedded in the attractions of Mairokang Beach Game (MBG). The study was conducted in conjunction with the time of the MBG implementation, on 20 - 26 October 2016. General public of Sangihe has conducted the MBG competition as a regular local cultural activity and has become an attraction for coastal tourism in the Sangihe Islands Regency but comprehensive planning needs to be made that is not only focused on tourists but also to stakeholders, local government and the general public. Therefore, government support in the development of coastal tourism in MBG is very necessary. The inclusion of MBG activities in the Pesona Sangihe tourism calendar is one of the steps taken by the Government of the Sangihe Islands Regency.
\end{abstract}

Keyword : Mairokang Beach Game, Bentung, Coastal Tourism

\begin{abstract}
Abstrak
Kabupaten Kepulauan Sangihe yang merupakan kabupaten bahari memiliki beberapa Kawasan Strategis Pariwisata yang memiliki fungsi utama pariwisata atau memiliki potensi untuk pengembangan pariwisata dan berpengaruh penting dalam satu atau lebih aspek seperti pertumbuhan ekonomi, sosial dan budaya, pemberdayaan sumber daya alam, daya dukung lingkungan hidup, pertahanan dan keamanan. Desa Bentung di Kecamatan Tabukan Selatan adalah salah satu desa di Kabupaten Kepulauan Sangihe yang mempunyai potensi dalam pariwisata pesisir. Atraksi wisata Mairokang Beach Game (MBG) merupakan lomba perahu tradisonal yang menjadi salah satu potensi pariwisata pesisir di Desa Bentung. Penelitian ini terfokus pada potensi pariwisata yang tersemat pada atraksi atraksi yang ada di Mairokang Beach Game (MBG). Penelitian dilakukan bersamaan dengan waktu pelaksanaan MBG yaitu pada tanggal 20 - 26 Oktober 2016. Masyarakat Sangihe telah melakukan lomba MBG sebagai kegiatan - kegiatan budaya lokal yang teratur dan menjadi daya tarik pariwisata pesisir di Kabupaten Kepulauan Sangihe namun perlu dibuat perencanaan menyeluruh yang tidak hanya terfokus pada turis tetapi juga pada stakeholder, pemerintah daerah dan masyarakat umum. Oleh karena itu, dukungan pemerintah dalam pengembangan pariwisata pesisir lomba MBG sangat diperlukan. Pemasukan kegiatan MBG dalam kalender pariwisata Pesona Sangihe merupakan salah satu langkah yang telah dilakukan oleh Pemerintah Daerah Kabupaten Kepulauan Sangihe.

Kata Kunci : Mairokang Beach Game, Bentung, Pariswisata Pesisir
\end{abstract}

PENDAHULUAN

Indonesia merupakan negara maritim, dengan luas wilayah perairan $6.315 .222 \mathrm{~km}^{2}$ dengan panjang garis pantai $99.093 \mathrm{~km}^{2}$ serta jumlah 13.466 pulau yang bernama dan berkoordinat (Badan Informasi Geospasial, 2015).

$$
\text { Indonesia dikenal sebagai }
$$

negara dengan biodiversity tinggi. Kondisi ini dapat dilihat pada keanekaragaman hayati yang tinggi, serta sumberdaya pesisir yang potensial untuk berbagai opsi pembangunan. Namun demikian dengan semakin meningkatnya pertumbuhan penduduk dan pesatnya kegiatan pembangunan di wilayah pesisir, seperti pembangunan pemukiman, pelabuhan, serta pusat perekonomian lainnya, maka tekanan ekologis terhadap ekosistem dan sumber daya pesisir makin meningkat. Meningkatnya tekanan ini dapat mengancam keberadaan dan kelangsungan ekosistem dan sumberdaya pesisir, laut dan pulaupulau kecil yang ada disekitarnya.

Pariwisata pesisir merupakan salah satu kegiatan yang memanfaatkan sumber daya pesisir tanpa merusak lingkungan, tetapi menambah devisa 
negara data. Berdasarkan data dari Kementrian Pariwisata ditahun 2015, jumlah wisatawan nusantara Indonesia sebanyak 187,3 juta dan jumlah wisatawan manca negara sebanyak 9,2 juta perjalanan.

Kabupaten Kepulauan Sangihe merupakan salah satu kabupaten di Provinsi Sulawesi Utara yang memiliki potensi di bidang wisata pesisir, dengan daya tarik kawasan seperti Gunung api bawah laut, pantai berpasir putih, keragaman biota laut dan keindahan terumbu karang. fishing ground dan mangrove.

Dinas Kebudayaan dan Pariwisata Kabupaten Kepulauan Sangihe yaitu Mairokang Beach Game (MBG) yang dilaksanakan di Desa Bentung Kecamatan Tabukan Selatan, dengan jenis atraksi berupa lomba balap perahu, yang dimulai pada tahun 2015. Karena adanya pergantian pemerintahan di Kabupaten Kepulauan Sangihe, pada tahun 2017 lomba tersebut tidak dilaksanakan. Lomba tersebut diharapkan menjadi agenda tahunan tetap di Kabupaten Kepulauan Sangihe.

\section{Perumusan Masalah}

Berdasarkan latar belakang maka dibuat rumusan masalah, yaitu bagaimana atraksi wisata pesisir yang ada di Desa Bentung.

\section{Tujuan dan Manfaat Penelitian}

Tujuan penelitian ini merupakan tindak lanjut dari masalah yang telah dirumuskan. Dengan kata lain tujuan yang ingin dicapai dalam penelitian ini adalah untuk mendeskripsikan atraksi wisata pesisir Mairokang Beach Game (MBG) di perairan Desa Bentung, Kecamatan Tabukan Selatan, Kabupaten Kepulauan Sangihe.

\section{Tempat dan Waktu Penelitian}

Penelitian ini dilaksanakan di Desa Arakan Kecamatan Tatapaan Kabupaten Minahasa Selatan Propinsi Sulawesi Utara.
Waktu yang diperlukan dalam melaksanakan penelitian ini mulai dari penyusunan rencana kerja penelitian sampai pada pelaksanaan ujian kurang lebih 6 bulan, yaitu dari bulan Februari 2018 sampai bulan Juli 2018.

\section{TINJAUAN PUSTAKA}

\section{Pariwisata}

Pariwisata (tourism) atau kepariwisataan adalah keseluruhan kegiatan yang terkait dengan pariwisata dan bersifat multidimensi serta multidisiplin yang muncul sebagai wujud kebutuhan setiap orang dan negara serta interaksi antara wisatawan dan masyarakat setempat, sesama wisatawan, Pemerintah, Pemerintah Daerah, dan pengusaha (UU 10/2009 tentang Kepariwisataan).

Pengertian pariwisata adalah suatu perjalanan yang dilakukan untuk sementara waktu, yang diselenggarakan dari suatu tempat lain, dengan maksud bukan untuk berusaha (business) atau mencari nafkah di tempat lain yang dikunjungi, tetapi semata-mata untuk menikmati perjalanan tersebut guna pertamasyaan dan rekreasi atau untuk memenuhi keinginan yang beraneka ragam (Yoeti, 1996).

\section{Pariwisata Pesisir}

Menurut Dahuri dkk., (2001) Kegiatan pariwisata memiliki banyak jenis baik pariwisata buatan dan pariwisata alam, dalam pariwisata alam ada beberapa bentuk kegiatan pariwisata, salah satu kegiatan pariwisata alam tersebut adalah kegiatan pariwisata pesisir.

Kegiatan wisata pesisir adalah kegiatan rekreasi yang dilakukan sekitar pantai seperti berenang, berselancar, berjemur, menyelam, snorkeling, berjalan-jalan atau berlari-lari di 
sepanjang pantai, menikmati keindahan suasana pesisir, dan bermeditasi.

\section{Destinasi Wisata}

Ketika melakukan perjalanan, pasti terdapat daerah yang dituju. Daerah inilah yang disebut Daerah Tujuan Wisata. Sesuai dengan Undangundang Republik Indonesia Nomor 10 Tahun 2009 Tentang Kepariwisataan, Daerah Tujuan Wisata yang selanjutnya disebut Destinasi Pariwisata adalah kawasan geografis yang berada dalam satu atau lebih wilayah administrasi yang di dalamnya terdapat daya tarik wisata, fasilitas umum, fasilitas pariwisata, aksesibilitas, serta masyarakat yang saling terkait dan melengkapi terwujudnya kepariwisataan. Destinasi Pariwisata harus memenuhi tiga syarat (Yoeti, 1996), yaitu:

1. Harus memiliki something to see, yaitu di tempat tersebut harus ada obyek dan atraksi wisata khusus, yang berbeda dengan apa yang dimiliki daerah lain untuk dilihat.

2. Harus menyediakan something to do, yaitu di tempat tersebut harus tersedia fasilitas untuk melakukan kegiatan reaksi yang dapat membuat betah wisatawan.

3. Harus menyediakan something to buy, yaitu di tempat tersebut harus tersedia fasilitas untuk belanja, terutama oleh-oleh dan barang kerajinan khas yang dapat dibawa pulang ketempat asal oleh wisatawan.

Daya tarik wisata adalah segala sesuatu yang memiliki keunikan, keindahan dan nilai yang berupa keanekaragaman kekayaan alam, budaya, dan hasil buatan manusia yang menjadi sasaran atau tujuan kunjungan wisatawan. Berhasilnya suatu tempat berkembang menjadi Daerah Tujuan Wisata (DTW) sangat tergantung pada tiga faktor utama (Samsuridjal \& Kaelany, 1997).

1. Atraksi:

a. Atraksi Tempat: Seumpamanya tempat dengan iklim yang baik, pemandangan yang indah atau tempat-tempat bersejarah

b. Atraksi Kejadian/ Pariwisata : Kongres, pameran atau peristiwa peristiwa olah raga, festival dan sebagainya.

2. Mudah dicapai (Aksesibilitas) :

Tempat tersebut dekat jaraknya, atau tersedia transportasi ke tempat itu secara teratur, sering, mudah, nyaman, dan aman.

3. Amenitas:

Tersedianya fasilitas-fasilitas seperti tempat penginapan, restoran, hiburan, transportasi, lokal yang memungkinkan wisatawan berpergian ke tempat itu serta alat-alat komunikasi lainnya.

\section{METODE PENELITIAN}

Metode penelitian yang digunakan adalah metode kualitatif Penelitian kualitatif bersifat deskriptif dan cenderung menggunakan pendekatan analisis induktif yang dilakukan melalui wawancara dan observasi terkait atraksi pariwisata pesisir Mairokang Beach Game di Desa Bentung.

Metode penelitian yang digunakan adalah metode kualitatif Penelitian kualitatif bersifat deskriptif dan cenderung menggunakan pendekatan analisis induktif yang dilakukan melalui wawancara dan observasi terkait atraksi pariwisata pesisir Mairokang Beach Game di Desa Bentung.

\section{Lokasi dan Waktu Penelitian}

Penelitian ini dilakukan di Desa Bentung Kecamatan Tabukan Selatan Kabupaten Kepulauan Sangihe Provinsi Sulawesi Utara. 


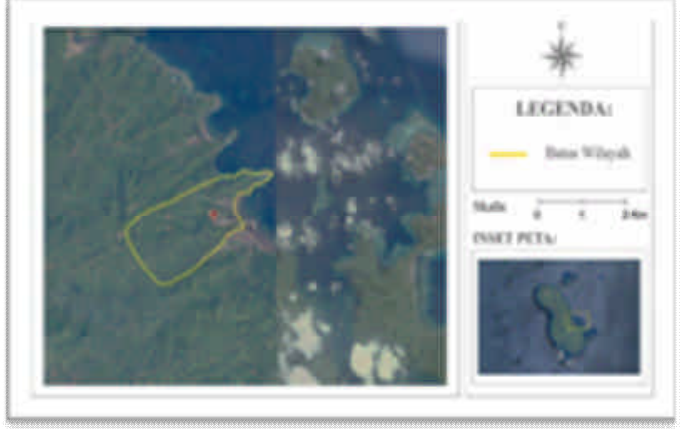

Gambar 1. Lokasi Penelitian

(Sumber : Google Earth, 05/11/2016)

Waktu yang diperlukan untuk melaksanakan penelitian selama delapan bulan yang dimulai pada bulan Januari sampai Agustus 2017

\section{Metode Pengumpulan Data}

Data diperoleh dari studi lapangan dan studi pustaka, pengamatan langsung dan wawancara. Uraian mengenai teknik pengumpulan data adalah sebagai berikut:

Studi Pustaka/Literatur

Studi pustaka merupakan kegiatan pengumpulan data penunjang berupa karya ilmiah, pelaporan, peraturan perundang-undangan dan tulisan-tulisan yang berhubungan dengan penelitian. Studi literatur dimaksudkan untuk mendapatkan konsep pengembangan kawasan pariwisata pesisir dan teori tentang pengembangan strategi kawasan pariwisata pesisir gambaran umum mengenai objek dan daya tarik yang ada di Desa Bentung yang kemudian diverifikasi di lapangan.

\section{Pengamatan lapangan/ Observasi}

Pengamatan langsung di lapangan merupakan metode pengumpulan data ekologis, sosial ekonomi dan budaya. Teknik yang digunakan dalam pengambilan data adalah check list. Dilakukan juga pengambilan titik koordinat pada masing- masing objek dan daya tarik wisata mengunakan GPS dan pengambilan dokumentasi di masing-masing objek dan daya tarik wisata di Desa Bentung.

\section{Wawancara}

Wawancara merupakan langkap pengumpulan data primer di lapangan yang bertujuan untuk memperoleh informasi lebih lanjut terkait penyusunan strategi pengembangan kawasan atraksi wisata pesisir berbasis mesyarakat. Alat pengambilan data dari wawancara dilakukan dengan pedoman wawancara.

Data yang dikumpulkan dalam penelitian meliputi data primer dan sekunder. Data primer diperoleh dari pengamatan langsung di lapangan (observasi) dan wawancara, berupa jumlah peserta, jalur balapan, jenis balapan MBG, persepsi masyarakat dan kebijakan terkait pengembangan pariwisata pesisir di Desa Bentung. Sedangkan data sekunder yang dikumpulkan dari hasil penelitian berupa kondisi fisik Desa Bentung, potensi jenis flora dan fauna serta kondisi sosial ekonomi masyarakat setempat.

\section{Atraksi Wisata Mairokang Beach Game}

Sesuai dengan implementasi visi Daerah Kabupaten Kepulauan Sangihe sebagai Kabupaten Bahari yang sejahtera dan bermartabat serta meningkatkan potensi bahari di Kabupaten Kepulauan Sangihe khususnya di Kecamatan Tabukan Selatan, Kampung Bentung melaksanakan kegiatan - kegiatan yang bernuansa budaya Sangihe seperti lomba Mairokang Beach Game (MBG). Pelaksanaan kegiatan tersebut dimaksudkan untuk mempromosikan pariwisata bahari di Kecamatan Tabukan Selatan. 
Kegiatan MBG menjadi salah satu tempat berkumpul beberapa masyarakat pesisir di Kabupaten Kepulauan Sangihe, pada kegiatan ini juga nelayan dan masyarakat mendukung kegiatan ini berlajut dengan keinginan masyarakat yang sedemikian sehingga lanjut didukung pemerintah dengan menjadikan kegiatan lomba MBG, merebutkan piala Bupati dengan maksud dan tujuan yaitu:

1. Mengembangkan dan melestarikan budaya Bahari di Kabupaten Kepulauan Sangihe.

2. Mempererat Persatuan dan Kesatuan masyarakat pesisir

3. Mengembangkan rasa peduli dan kepekaan sosial antar umat beragama

Kegiatan Lomba MBG baru berlangsung yang kedua kalinya di tahun 2016, kegiatan lomba MBG pertama di mulai pada Tahun 2015 dan akan dilaksanakan di tiap tahunnya tapi ditahun 2017 tidak dilaksanakan karena masalah pergantian pemerintah dan akan dilaksanakan lagi di tahun berikutnya jika ada bantuan dana dari pemerintah Kabupaten Kepulauan Sangihe dan kegiatan ini akan terus di selengarakan pada pantai Desa Bentung (Mairokang). Adapun beberpa kegiatan yang di lombakan semua berhubungan dengan balapan perahu. Jenis Kegiatan/ Lomba yaitu:

1. Perahu Dayung 2 Orang Putri

2. Perahu Dayung 1 Orang Putra

3. Perahu Dayung 2 Orang Putra

4. Perahu Motor Berkekuatan 5,5 PK

5. Perahu Motor Berkekuatan $13 \mathrm{PK}$

6. Perahu Motor Berkekuatan 16 PK

7. Motor Speed Berkekuatan 40 PK

8. Perahu Pakura Berkekuatan 16 PK

\section{Deskripsi Kegiatan}

Pembukaan kegitan MBG II, dimulai pada tanggal 20 Oktober 2016 dan kegiatan tersebut dibuka secara langsung oleh Bupati Kabupaten Kepulauan Sangihe, dan selanjutnya dimulai dengan lomba balap 2 Orang Putri dengan jumlah peserta 8 peserta dan lanjut dengan Lomba Dayung Putra 1 dan 2 Orang dengan jumlah peserta 15 peserta Jarak Kegiatan 150 Meter ke arah laut dari pantai mairokang dan balik kepantai dengan jumlah keseluruhan jarak lomba dayung 300 Meter. Kegiatan lomba di hari pertama diselenggarakan hingga fase semi final dan untuk lomba final dilaksanakan di hari terakhir (26 Oktober 2016).

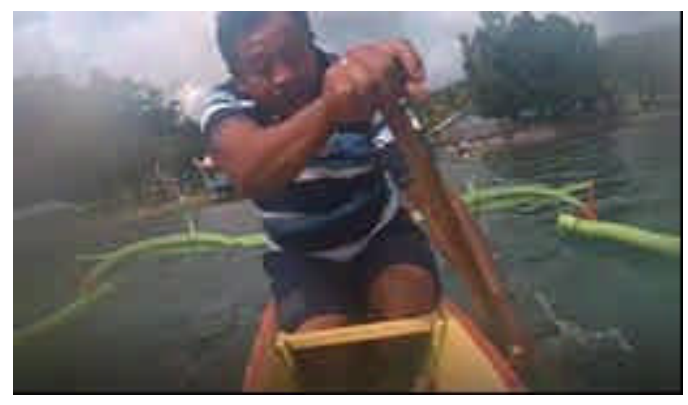

Gambar 2. Lomba Balap Perahu dayung MBG

Kegiatan lomba yang dilaksanakan di hari selanjutnya (21 Oktober 2016) adalah Lomba Perahu Motor Berkekuatan 5,5 PK. Kegiatan ini juga dilaksanakan hingga semifinal, tiap kegiatan 3 peserta agar mengurangi resiko terjadi tabrakan antar perahu. Setiap kegiatan lomba balap perahu mesin kecuali Motor Speed semua perahu start dari pantai Laotongan di pulau Tehang.

Kegiatan Lomba Perahu motor berkekuatan 5,5 PK jumlah peserta 17 Peserta dan untuk yang berkekuatan 13 PK jumlah peserta 23 Peserta dan untuk 16 PK jumlah peserta 15 peserta dan untuk Perahu Pakura jumlah peserta 8 peserta Jarak lomba 2,5 Km dari pantai 
Laotongan sampai pantai Mairokang Bentung. Lomba speed berkekuatan 40 PK, dengan jumlah peserta 4 peserta menjadi lomba yang ditungu-tungu oleh para masyarakat atau para penonton. Lomba balap perahu ini memiliki rute terjauh berjarak $14,5 \mathrm{Km}$ dalam balapan dengan garis start dan finish dari pantai Mairokang Bentung.

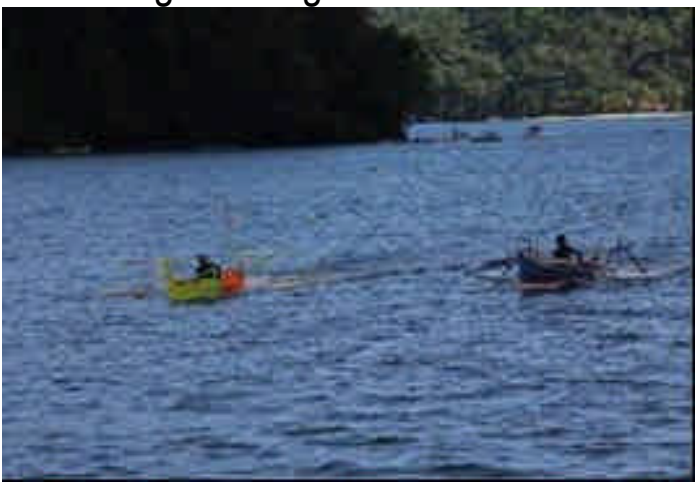

Gambar 3. Lomba Perahu Motor 5,5 PK

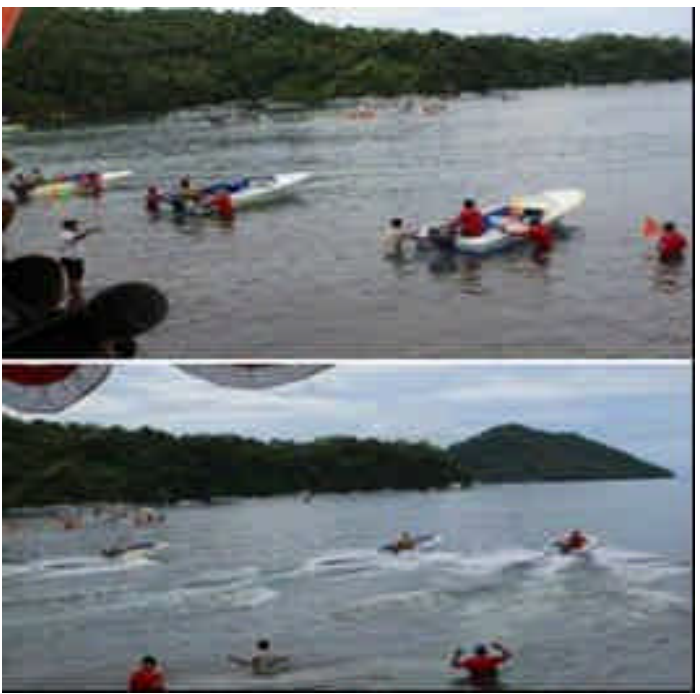

Gambar 4. Lomba Motor Speed Berkekuatan 40 PK

Lomba speed berkekuatan 40 PK, dengan jumlah peserta lima peserta menjadi lomba yang ditungu-tungu oleh para masyarakat atau para penonton. Lomba balap perahu ini memiliki rute terjauh dalam balapan dengan garis start dan finish dari pantai Mairokang Bentung. Rute jalur balapan perahu sejumlah kegiatan MBG dapat dilihat pada Gambar 5.

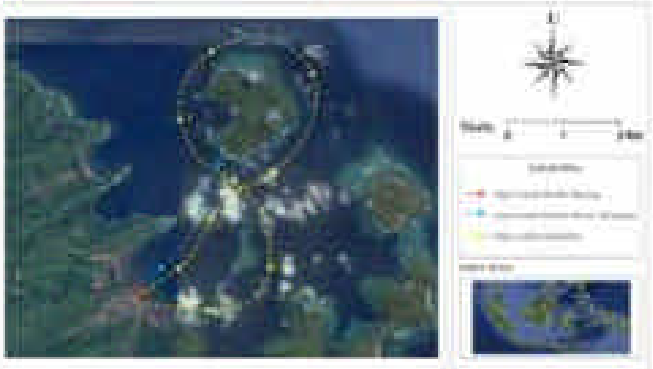

Gambar 5. Peta Jalur Lomba MBG (Sumber : Google Earth, 2016)

Kegiatan lomba ini sangat diapresiasi masyarakat, dengan jumlah penonton yang banyak dalam menonton kegiatan lomba MBG ini, dan diharapkan akan terus menjadi daya tarik pariwisata di Desa Bentung Kecamata Tabukan Selatan.

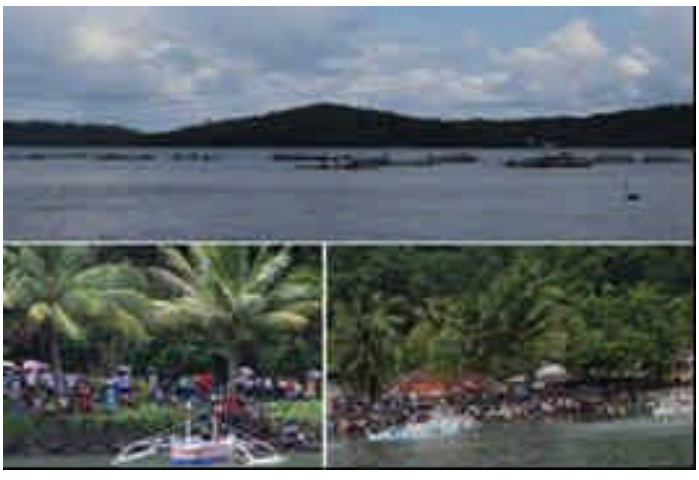

Gambar 6. Penonton MBG

Kegiatan atraksi wisata Mairokang Beach Game baru saja dimasukkan dalam kalender wisata di Kabupaten Sangihe. Kegiatan ini memiliki kelebihan jika dibandingkan dengan lomba yang sudah masuk dalam kalender pariwisata nasional seperti lomba Manggurebe Arumbae yang hanya terdiri dari dua kegiatan lomba balap perahu (Kertopati, 2016) :

$$
\text { Lomba balap perahu }
$$

Manggurebe Arumbae, Ambon.

1. Lomba perahu tradisional atau Manggurebe Arumbae adalah lomba balapan mendayung perahu hingga batas terakhir. Satu perahu terdiri dari 28-31 peserta lelaki. 
2. Lomba perahu semang (bercadik), yakni lomba balapan perahu di laut yang didayung oleh perempuan yang memakai pakaian tradisional Maluku.

Kegiatan Mairokang Beach

Game berkembang dari tahun ke tahun. Terjadi pertumbuhan peserta di tahun 2015 jumlah peserta 52 peserta dan jumlah peserta bertambah hingga 79 peserta pada tahun 2016. Dengan perkembangan seperti ini, diharapkan peserta bukan hanya masyarakat Kabupaten Kepulauan Sangihe saja tapi seluruh masyarakat Indonesia.

\section{KESIMPULAN}

dari perdasarkan hasil pembahasan disimpulkan bahwa kegiatan MBG merupakan budaya lokal yang yang telah dilaksanakan secara teratur dan menjadi daya tarik pariwisata pesisir di Kabupaten Kepulauan Sangihe namun perlu dibuat perencanaan menyeluruh yang tidak hanya terfokus pada turis tetapi juga pada stakeholder, pemerintah daerah dan masyarakat umum.

\section{SARAN}

Dukungan pemerintah dalam pengembangan pariwisata pesisir lomba MBG sangat diperlukan. Pemasukan kegiatan MBG dalam kalender pariwisata Pesona Sangihe merupakan salah satu langkah yang telah dilakukan oleh Pemerintah Daerah Kabupaten Kepulauan Sangihe.

\section{DAFTAR PUSTAKA}

Badan Informasi Geospasial., 2015. Informasi Geospasial Dukung Pembangunan Poros Maritim. www.bakosurtanal.go.id

Kertopati, L., 2016. Mengarunggi Tradisi Maluku dengan Manggurebe Arumbare. CNN Indonesia, viewed 22 September 2017, from https://m.cnnindonesia.com/hiburan/mengaru ngi-tradisi-maluku-dengan-manggurabearumbae/

Samsuridjal \& Kaelany., 1997 : 21, dalam Journal Ruas, Vol 4 No.1, Juni 2006

Undang-undang Republik Indonesia Nomor 10 Tahun 2009 tentang Kepariwisataan. Bumi Aksara : Jakarta.

Yoeti, O, A., 1996. Pengantar IImu Pariwisata. Bandung: Angkasa. hlm 178. 
Available online :http://ejournal.unsrat.ac.id/index.php/akulturasi 